\title{
BMJ Open Quality Elective cardiovascular care in the era of the COVID-19 pandemic: managing tragic choices
}

\section{Adam E Berman (D , , ${ }^{1,2}$ Douglas Miller, ${ }^{1,3}$ Robert A Sorrentino, ${ }^{1}$ Elias A Mossialos ${ }^{4}$}

To cite: Berman AE, Miller D, Sorrentino RA, et al. Elective cardiovascular care in the era of the COVID-19 pandemic: managing tragic choices. BMJ Open Quality 2020;9:e001069. doi:10.1136/ bmjoq-2020-001069

Received 17 June 2020 Revised 31 August 2020 Accepted 18 September 2020
Check for updates

(C) Author(s) (or their employer(s)) 2020. Re-use permitted under CC BY-NC. No commercial re-use. See rights and permissions. Published by BMJ.

${ }^{1}$ Division of Cardiology, Medical College of Georgia, Augusta, Georgia, United States ${ }^{2}$ Division of Health Economics and Modeling, Medical College of Georgia, Augusta, Georgia, United States

${ }^{3}$ Division of Health Policy, Medical College of Georgia, Augusta, Georgia, United States ${ }^{4}$ Department of Health Policy, The London School of Economics and Political Science, London, UK

Correspondence to

Dr Adam E Berman; aberman@augusta.edu

\section{ABSTRACT}

The COVID-19 pandemic has led to significant morbidity and mortality globally. As health systems grapple with caring for patients affected with COVID-19, cardiovascular procedures that are deemed 'elective' have been postponed. Guidelines concerning which cardiac procedures should be performed during the pandemic vary by specialty and geography in the USA. We propose a clinical heuristic to guide individual physicians and governing bodies in their decision making regarding which cardiac procedures should be performed during the COVID-19 pandemic using the behavioural economics concept of heuristics and ecological rationality.

\section{COVID-19 AND CARDIOVASCULAR MEDICINE}

Chinese healthcare officials described a novel coronavirus in December 2019 (COVID-19) that was responsible for an acute respiratory illness, leading to death in $3 \%-4 \%$ of cases to date. ${ }^{1}$ In the following months, the coronavirus outbreak was declared a global pandemic by the $\mathrm{WHO}$, and the number of cases in the USA continued to rise. ${ }^{2}$ As of this writing, over 25 million confirmed cases have been reported globally, of which 843238 affected individuals have died of COVID-19related illnesses. ${ }^{3}$

The response of the cardiovascular (CV) community across the world has been brisk. Although COVID-19 has been reported to cause myocardial injury and even fulminant myocarditis, the majority of COVD-19-related mortality is driven by pulmonary injury particularly in elderly populations. ${ }^{4}$ In light of these growing clinical concerns, hospitals across the USA and the world were faced with the challenge of restricting access to some forms of CV care. CV care delivery in both outpatient, office-based settings and inpatients settings has been affected. One example of this is the cancellation of 'elective' CV procedures. On 18 March 2020, the Centers for Medicare \& Medicaid Services (CMS), the federal agency that sets US healthcare policy and reimbursement regulations, announced that all elective surgeries and medical and dental procedures would be postponed during the COVID-19 pandemic largely due to the need to restrict the non-urgent use of personal protective equipment. $^{56}$

\section{TRAGIC CHOICES IN THE ERA OF COVID-19}

In their 1978 classic work Tragic Choices, Calabresi and Bobbitt describe how under extraordinary circumstances, society is forced to make difficult choices on deriving from a scarcity of goods and services. ${ }^{7}$ Tragic choices arise from the conflicts that arise when a society is forced to decide who benefits from the distribution of resources in austere environments of scarcity and that society's inherent moral values. Calabresi and Bobbitt, both economists and legal scholars, go on to state, 'The object of public policy must be, therefore, to define with respect to each particular tragic choice, that combination of approaches which most limits tragedy and which deals with that irreducible minimum in the least offensive way'. Viewed then through the lens of healthcare policy, the painful choices facing the global medical community during the current COVID-19 outbreak are striking, yet in some circumstances, unavoidable.

On 16 March 2020, the Società Italiana Di Anestesia Analgesia Rianimazione E Terapia Intensiva released an urgent publication entitled 'Clinical Ethics Recommendations for the Allocation of Intensive Care Treatments, In Exceptional, Resource-Limited Circumstances'. In this telling document, a group of experts from their respective medical society outlined the potential need for specifying the allocation of scarce healthcare resources in the face of the COVID-19 outbreak. These measures include potentially defining an age limit for admission to the intensive care unit, withholding invasive mechanical ventilation and maximising the benefits of resource allocation for the greatest number of patients. These recommendations mirror guidelines invoked during wartime or disaster medicine typified by extreme limitations to the access of medical care and health resources. 


\section{DEFINING ELECTIVE CV PROCEDURES AND THEIR CLINICAL} ECOSYSTEMS

Despite a uniform desire within the CV community to support vigorous efforts in the fight against COVID-19, heterogeneous opinions were proposed as to which CV procedures should be deemed elective. The American College of Surgeons (ACS) released clinician guidelines concerning those surgical procedures that should be delayed during the COVID-19 outbreak. ${ }^{9}$ Importantly, the ACS emphasises the role of the surgeon's expertise in making a determination as to the necessity of proceeding with surgery during these extraordinary times. Emanating from these recommendations was a procedural framework created by clinicians in St Louis, MO. that designated the Elective Surgery Acuity Scale (ESAS). Following the dissemination of the ESAS framework, the CMS adopted and amended this tiered framework to include broad classifications of $\mathrm{CV}$ procedures. ${ }^{5}$

Across the USA, elective cardiac procedures are performed in a wide variety of settings including ambulatory care facilities, outpatient surgical centres and traditional hospital settings. Each of these clinical venues differ in its respective exposure to caring for patients either exposed to or infected with COVID-19. Consequently, the decision to perform an elective cardiac procedure impacts multiple stakeholders. The patient undergoing treatment is expected to benefit from it, but in so doing, may be exposed to COVID-19 from the clinical environment of care. Likewise, $40 \%-50 \%$ of all patients infected with COVID-19 but not yet exhibiting symptoms may serve as a vector to other patients or providers within a clinical ecosystem. Additionally, elective patients may consume vital healthcare material and/or human resources that would be better allocated to sicker patients as supply chain management becomes an increasing concern among hospitals and clinics.

Given the broad discretion encompassed within the CMS tiered framework, some US health systems continued to proceed with elective CV procedures while others restricted them. This heterogeneity has led to confusion among some CV caregivers as to which procedures should be performed and which should be deferred. The US healthcare system largely relies on a fee-for-service reimbursement model at both practitioner and facility levels. Thus, the financial and economic impact of elective procedure cancellations may be substantial and uneven across US healthcare delivery systems. ${ }^{10}$ The business survival of many healthcare systems, normally supported by elective surgeries and procedures, has been placed at real risk. This represents yet another valid reason health systems and clinicians alike sought clarification from the US federal government and professional societies regarding which procedures should proceed and which should be postponed. Fortunately, several major US CV professional societies offered practitioners better guidance for which procedures should and should not be delayed during the COVID-19 crisis. $^{11-13}$
Beyond financial concerns, the impact of the COVID-19 pandemic on clinical outcomes is only now beginning to be realised. Early reports of significantly lower hospitalisations for common $\mathrm{CV}$ conditions such as acute myocardial infarction and higher rates of out of hospital cardiac arrest suggest a potential avoidance of care on the part of patients owing to reduced caregiver access or fear of acquiring COVID-19 in-hospital. ${ }^{14-18}$ These aversion behaviours may ultimately lead to greater CV morbidity and mortality than during similar historical time periods. Coupled with reduced hospitalisation rates would be a decline in appropriate CV procedural activity. For example, a review of diagnostic cardiac catheterisation volumes occurring within a large consortium of tertiary care cardiac centres revealed a significant reduction in procedural volumes when compared with prior years' data. ${ }^{15}$ Thus, the COVID-19 pandemic has created an environment of uncertainty on the part of patients and clinicians alike. These uncertainties may unfortunately lead to poorer long-term clinical outcomes, worsened health system financial positions and erosion of patient confidence in entering healthcare facilities.

\section{TOWARDS A SIMPLIFIED DECISION-MAKING TOOL FOR CV CLINICIANS CONSIDERING 'ELECTIVE' CV PROCEDURES}

The guidance of specialty-specific professional societies is invaluable to practising CV clinicians in these uncertain times. Although helpful, the clinical scenarios confronting cardiology specialists at healthcare systems across the USA during the pandemic remained highly variable. Increasingly, CV physicians were forced to weigh the pros and cons of proceeding with not only elective cardiac procedures but in some instances, outpatient preprocedural consultation also.

In light of these findings, we propose a simplified, yet widely applicable heuristic to aid clinicians in their medical decision-making process in these times of heightened uncertainty. Heuristics are decision-support tools that have been well described in the psychological and behavioural economics literature. During the COVID-19 crisis, medical decision making in healthcare has been increasingly being made under uncertainty. Incomplete information leads to diagnostic ambiguities that render treatment decisions more difficult. ${ }^{19}$ As such, our framework for creating care plans may be viewed as occurring with the environment of ecological rationality as advocated by Gigerenzer. ${ }^{202}$ Within the domain of ecological rationality, heuristics serve individuals to function within a dynamic environment, an environment that may or may not be rational in the classical sense. As the COVID-19 pandemic has resulted in global tumult, simple heuristics may be of help to practising clinicians in allocating CV services while functioning in an 'irrational' environment.

Consequently, we propose the following heuristic to be considered during the ongoing pandemic: clinicians may choose to proceed with elective CV procedures aligned 
with clinical guidelines after discussion with patients if all of the following conditions are $\mathrm{met}^{5}$ :

- The procedure may take place in a clinical environment commensurate with usual care if the patient meets conventional clinical indications for that procedure following appropriate diagnostic evaluation in an environment that minimises the risk of infection.

- Neither the patient nor any member of the procedural team is actively infected with COVID-19.

- By performing the procedure, the patient and care team will consume fewer total healthcare resources than they would if the procedure had not been performed.

- Procedural performance will not overtly disadvantage a sicker patient in the immediate respective clinical environment.

Cognizant of the potential for unintentional selection bias inherent when clinicians are forced to prioritise and allocate precious and scarce human and material resources, it could be considered that the decision to proceed with elective $\mathrm{CV}$ procedures could be vetted by a local multidisciplinary CV care team, thereby supporting the individual physician's decision to proceed or delay care. Further, clinicians opting to proceed with elective CV procedures should be mindful of that patient's non-cardiac comorbidities and the potential for creating a need for the involvement of other non-CV specialists whose capacity to support that patient's needs may strain their capacity to care for other, sicker patients. Although the long-term effects of the COVID-19 pandemic on clinical cardiac outcomes remain unknown, a strategy aimed at unifying clinical decision making across and within complex and highly variable care environments via using heuristics may help preserve high-quality CV care and measurable patient outcomes during times of unprecedented uncertainty. ${ }^{22}$

We acknowledge that no heuristic framework is perfect, and we recognise that individual caregivers and health systems have been forced to make difficult decisions under dynamic conditions conferring substantial uncertainty. Similar to our Italian colleagues, extraordinary decisions may have to be made that defy our usual customs. Nonetheless, we believe that having created an easily applied heuristic may be of benefit to other frontline caregivers who struggled with making the decision on how best to deliver CV care to patients in need during exceptionally difficult times.

\section{CONCLUSIONS}

The COVID-19 pandemic has placed an extraordinary strain on the global healthcare delivery system. CV caregivers have struggled with medical decision making in many instances during these uncertain times. In our experiences, clinical heuristics developed for elective $\mathrm{CV}$ procedures within what can be regarded as an environment of ecological rationality may afford CV clinicians with additional tools helped us manage the tragic choices presented by COVID-19 while minimising what could be tragic outcomes to our patients, staff and population.

Contributors All authors created to the conceptual development, writing and editing of this manuscript.

Funding The authors have not declared a specific grant for this research from any funding agency in the public, commercial or not-for-profit sectors.

Competing interests None declared.

Patient and public involvement Patients and/or the public were not involved in the design, or conduct, or reporting, or dissemination plans of this research.

Patient consent for publication Not required.

Provenance and peer review Not commissioned; externally peer reviewed.

Data availability statement There are no data in this work.

Open access This is an open access article distributed in accordance with the Creative Commons Attribution Non Commercial (CC BY-NC 4.0) license, which permits others to distribute, remix, adapt, build upon this work non-commercially, and license their derivative works on different terms, provided the original work is properly cited, appropriate credit is given, any changes made indicated, and the use is non-commercial. See: http://creativecommons.org/licenses/by-nc/4.0/.

ORCID iD

Adam E Berman http://orcid.org/0000-0002-9023-1130

\section{REFERENCES}

1 Wang C, Horby PW, Hayden FG, et al. A novel coronavirus outbreak of global health concern. Lancet 2020;395:470-3.

2 World Health Organization. March 11, 2020. Available: https:// www.who.int/dg/speeches/detail/who-director-general-s-openingremarks-at-the-media-briefing-on-covid-19-11-march-2020 [Accessed 20 Mar 2020].

3 Johns Hopkins University coronavirus resource center. Available: https://coronavirus.jhu.edu/map.html [Accessed 28 Aug 2020].

$4 \mathrm{Hu} \mathrm{H}$, Ma F, Wei X, et al. Coronavirus fulminant myocarditis saved with glucocorticoid and human immunoglobulin. Eur Heart $J$ 2020:ehaa190.

5 US center for Medicare and Medicaid services. Available: https://www.cms.gov/newsroom/press-releases/cms-releasesrecommendations-adult-elective-surgeries-non-essential-medicalsurgical-and-dental [Accessed 20 Mar 2020].

6 US center for Medicare and Medicaid services. Available: https:// www.cms.gov/files/document/31820-cms-adult-elective-surgeryand-procedures-recommendations.pdf [Accessed 20 Mar 2020].

7 Calabresi G, Bobbitt N. Tragic choices. New York, NY: W. W. Norton \& Company, 1978.

8 Societ Italiana di Anestesia analgesia Rianimazione E Terapia Intensiva. Available: http://www.siaarti.it/SiteAssets/News/ COVID19\%20-\%20documenti\%20SIAARTI/SIAARTI\%20-\% 20Covid-19\%20-\%20Clinical\%20Ethics\%20Reccomendations.pdf [Accessed 19 Mar 2020].

9 American College of surgeons. Available: https://www.facs.org/ about-acs/covid-19/information-for-surgeons/triage [Accessed 20 Mar 2020].

10 National Law Review. How to handle elective surgeries and procedures during the COVID-19 pandemic.. Available: https://www. natlawreview.com/article/how-to-handle-elective-surgeries-andprocedures-during-covid-19-pandemic [Accessed 18 Mar 2020].

11 Society for cardiovascular angiography and interventions. Available: http://www.scai.org/Presidents.aspx?cid=858f3f06-cad7-4ddb83e9-ee82bdc4793b\#.Xndd5C2ZPyJ [Accessed 21 Mar 2020].

12 Heart Rhythm Society. Available: https://www.hrsonline.org/ COVID19-Challenges-Solutions/Message01 [Accessed on March 20, 2020].

13 Wood DA, Mahmud E, Thourani VH, et al. Safe reintroduction of cardiovascular services during the COVID-19 pandemic: from the North American Society leadership. J Am Coll Cardiol 2020;75:3177-83.

14 Bhatt AS, Moscone A, McElrath EE, et al. Fewer hospitalizations for acute cardiovascular conditions during the COVID-19 pandemic. $J$ Am Coll Cardiol 2020;76:280-8.

15 Garcia S, Albaghdadi MS, Meraj PM, et al. Reduction in STsegment elevation cardiac catheterization laboratory activations in 
the United States during COVID-19 pandemic. J Am Coll Cardiol 2020;75:2871-2.

16 Wilson SJ, Connolly MJ, Elghamry Z, et al. Effect of the COVID-19 pandemic on ST-segment-elevation myocardial infarction presentations and in-hospital outcomes. Circ Cardiovasc Interv 2020;13:e009438.

17 Holland M, Burke J, Hulac S, et al. Excess cardiac arrest in the community during the COVID-19 pandemic. JACC Cardiovasc Interv 2020;13:1968-9.

18 Huynh K. Reduced hospital admissions for ACS - more collateral damage from COVID-19. Nat Rev Cardiol 2020;17:453.
19 Manski CF. Diagnostic testing and treatment under ambiguity: using decision analysis to inform clinical practice. Proc Natl Acad Sci U S A 2013;110:2064-9.

20 Dekker E, Remic B. Two types of ecological rationality: or how to best combine psychology and economics. Journal of Economic Methodology 2019;26:291-306.

21 Gigerenzer G, Selten R. Bounded rationality: the adaptive toolbox. Cambridge, MA: MIT Press, 2001.

22 Islam R, Weir C, Del Fiol G. Heuristics in managing complex clinical decision tasks in experts' decision making. IEEE Int Conf Healthc Inform 2014;2014:186-93. 